\title{
NANOSPHERE-LOADED TADALAFIL WITH ENHANCED ORAL BIOAVAILABILITY: INNOVATIVE APPLICATION OF ELECTROHYDRODYNAMIC TECHNIQUE
}

\author{
MOHAMMED M. MEHANNA', JANA K. ALWATTAR ${ }^{2}$ \\ 1,2Department of Pharmaceutical Technology, Faculty of Pharmacy, Beirut Arab University, Beirut, Lebanon \\ Email: mmhanna@bau.edu.lb
}

Received: 12 Aug 2019, Revised and Accepted: 25 Oct 2019

\begin{abstract}
Objective: Electrohydrodynamic atomization is a technique that utilizes electrical potential differences for the fabrication of particles ranging from nano to micrometer size, where the ultra-charged droplets of drug-loaded mist deposit as nanospheres after solvent evaporation. The drug-loaded polymeric spherical nanocomposites have a small volume with large surface area, which is a beneficial characteristic for dissolution and
\end{abstract} bioavailability enhancement of class II drugs.

Methods: This facile approach is employed for the preparation of tadalafil-loaded nanosystems, a class II drug used for erectile dysfunction treatment. Tadalafil-loaded nanoparticles prepared with different polymer concentrations were evaluated through process yield, drug loading, morphology and functional performance. Further, drug solid-state and compatibility of formulation components were assessed.

Results: The results obtained pointed out that nanoparticles were of uniform spherical morphologies with a size range between $1279 \pm 141$ and $374 \pm 13 \mathrm{~nm}$. The system maintained a high loading efficacy of $88 \%$, with most of the loaded drug released within 2 min during the in vitro dissolution studies. The differential scanning calorimetry, X-ray diffraction and Fourier-transform infrared spectroscopy demonstrated the presence of tadalafil in an amorphous form or as a molecular dispersion within the polymer matrix.

Conclusion: Tadalafil-loaded nanoparticles manufactured through this methodology is qualified as a strategy to ameliorate its solubility and bioavailability.

Keywords: Dissolution enhancement, Electrohydrodynamic atomization, Tadalafil, Nanoparticles, Nanosphere

(c) 2020 The Authors. Published by Innovare Academic Sciences Pvt Ltd. This is an open-access article under the CC BY license (http://creativecommons.org/licenses/by/4.0/) DOI: http://dx.doi.org/10.22159/ijcpr.2020v12i1.36828. Journal homepage: https://innovareacademics.in/journals/index.php/ijcpr

\section{INTRODUCTION}

Electrohydrodynamic methodology is an electrospraying technique, which is applied for the preparation of nano/microparticles. Electrohydrodynamic atomization as a pharmaceutical technique is highly dependent on both process and formulation factors, which in turn affect the final product characteristics. The formulation parameters such as the polymer type, concentration, and solvent properties, and the process features viz, flow rate and applied voltage, control the particle size/shape, drug loading and yield [1]. Electrohydrodynamic atomization is a single-step method which is able to produce monodisperse nanodroplets that solidify into nanospheres. Electrohydrodynamic atomization with its various advantages including high drug loading efficiency, particle size monodispersity, and ability to scale up, has been applied pharmaceutically for the preparation of polymeric nano/microparticles for drug delivery purposes as including enhancement oral bioavailability of celecoxib [2], paclitaxel [3], and mefenamic acid [4].

The interest in nano-sized particles has emerged in scientific research in the past decade. This system offers small volume and high surface area which presents beneficial property to overcome bioavailability complications that is a major challenge especially for drugs belonging to BCS class II [5]. Many techniques have evolved for the preparation of drug-loaded nanospheres including spray drying [6], coacervation [7], emulsification [8] and solvent evaporation [9]; however, most of these methods demonstrate some restrains namely, limitation to scale up, polydispersity of particles size, and low drug loading [10]. The drawbacks associated with the later conventional methods might be subsided by utilizing the electro hydrodynamic atomization technique for the preparation of drug-loaded nanospheres. This technique involves the spraying of a polymer solution containing the drug in a suitably conductive solvent under the influence of the electrical field.
Tadalafil is a recently approved, selective inhibitor of cyclic guanosine monophosphate (cGMP), specifically phosphodiesterase (PDE-5) and is commonly used for the treatment of erectile dysfunction and pulmonary hypertension [11]. This impotency-curative agent acts by amplifying the activity of the nitric oxide-signaling pathway which potentiates smooth muscle relaxation and results in vasodilation. Compared to other drugs used to control erectile dysfunction as seldinafil and verdinafil, tadalafil conserves a longer duration of actions (up to $36 \mathrm{~h}$ ) with less than $0.1 \%$ potential to cause vision abnormalities [12]. With these merits, tadalafil has gained widespread use yet its low aqueous solubility results in poor dissolution in the GIT fluid and poor variable bioavailability [13].

According to the BCS, drugs categorized into class II drug demonstrates a low aqueous solubility and a high permeability, which limits its therapeutic activity and clinical response [14]. Tadalafil belongs to this class of drugs; therefore many techniques have been used with the aim to enhance its dissolution characteristic as an attempt to improve its oral bioavailability include; complexation via beta-cylcodextrin [15], solid dispersion [16], cocrystal [17], liquisolid compact [13], and inclusion techniques [18]. The solubility enhancement of tadalafil through these methods reflected on a faster release of the drug, this allowed the released molecule to be passively partitioned within the GIT, resulting in a rapid onset of action and enhanced one bioavailability.

In the light of the virtues attained by the electro hydrodynamic atomization technique, tadalafil-loaded polymeric nanospheres were fabricated as an avenue to enhance its dissolution and bioavailability enhancement. Electrohydrodynamic atomization is introduced as an efficient, cost-effective and simple technique for the production of polyvinylpyrrolidone (PVP)/polyethylene oxide (PEO) nanosize particles. In our study the particle morphology and dissolution parameters with the polymer concentration variation was investigated for the determination of the optimal conditions for nanospheres fabrication. 


\section{METHODS AND MATERIALS}

Tadalafil was a generous gift from Benta pharma industry (Dbayeh, lebanon). Polyvinylpyrrolidone (PVP K60, MW=360 000), polyethylene oxide (PEO, MW= 35000-40000) were selected as the polymer matrix, methanol and hydrochloric acid were purchased from sigma aldrich (Steinheim, Switzerland). All other solvents and excipients utilized were of analytical grade.

\section{Preparation of tadalafil-loaded polymeric nanospheres}

In this study, for the preparation of the polymeric carriers, tadalafilloaded nanospheres were fabricated using an electrohydrodynamic atomization process. The drug-loaded polymeric solution was prepared through dissolving the appropriate amount of drug, PVP and PEO as present in table 1 in the suitable solvent and mixing until a clear solution is formed [2]. Methanol was utilized as a solvent as it maintains the required features, where it is suitable for solubilizing the drug and polymers on one hand and is rapidly evaporated for the successfulness of the electrohydrodynamic atomization process on the other hand [19]. The solution is loaded into a mechanical syringe pump with a 22 gauge tip stainless steel needle acting as a nozzle. The flow was controlled mechanically at a rate of $0.1 \mathrm{ml} / \mathrm{hr}$, a high voltage DC power supply of $23 \mathrm{KV}$ supplying electrical field with positive polarity attached to the dispensing tip and negative polarity to the collector site. Electrohydrodynamic atomization was performed through cone-jet mode in a closed, temperature-controlled chamber at $25 \pm 0.5^{\circ} \mathrm{C}$. Samples were collected on an aluminum foil which had been placed over the collector. Upon completion of the process, the nanospheres are removed from the collector surface and stored in a vacuum desiccator for further characterization.

\section{Electrospray powder process yield}

The drug-loaded polymeric nanosphere yield was determined gravimetrically as the ratio between the weight of the dried powder collected and the weight of polymers and drug-loaded into the equipment [20].

\section{Drug loading efficiency}

After the selection of the optimized processing conditions for the establishment of tadalafil-loaded nanospheres, various polymer (PVP/PEO) weight ratios were studied to optimize the final preparation characteristics. Tadalafil-loaded into the nanoparticles was determined by dissolving a specific weight of the formulation in methanol-water solution (1:1) and its content was measured using UV spectrophotometer (Optima, SP-3000 PLUS, Tokyo, Japan) at $\lambda \max 284 \mathrm{~nm}$. The loading efficacy of the prepared formulation is the ratio of the amount loaded into the nanoparticles to the total amount of drug in the fed solution [21]

\section{In vitro release measurement}

The in vitro release profiles of tadalafil from the nanospheres formulations, free drug and physical mixture were determined using dissolution apparatus I (ERWEKA, Heusentamm, Germany). Samples containing tadalafil equivalent to $10 \mathrm{mg}$ were filled into capsules (size 5). The samples were placed in $900 \mathrm{ml} 0.1 \mathrm{HCl}$ medium at 37 ${ }^{\circ} \mathrm{C} \pm 0.5$ under continuous stirring at $50 \mathrm{rpm}$ for a period of $60 \mathrm{~min}$. Aliquots of the media $(5 \mathrm{ml})$ were taken at preselected time intervals and passed through 0.22 Millipore filter, and drug content was determined spectrophotometrically [22].

\section{Nanosphere particle size and morphology}

Photomicroscopical analysis of different formulations was characterized to identify their surface characteristics and diameters using a scanning electron microscope (SEM) (SERON technology, AIS2300C, Korea). The collected samples were fixed on a double adhesive tape and sputter-coated with gold at less than 0.1 millibar pressure and $20 \mathrm{~mA}$. The morphology of the nanopheres was scanned at different fields and magnifications. The images obtained were utilized for calculating of the nanosphere diameter and polydispersity using image J software. For each determination, a sample of 100 nanoparticles was measured [23].

\section{Solid-state characterization \\ Differential scanning calorimetry (DSC)}

The thermograms of different samples were recorded using DSC (DSC60, schimadzu, Massachusetts, United states). Optimized formulation, physical mixture, free drug and polymers were enclosed in an aluminum pan, with a nitrogen flow rate of 25 $\mathrm{ml} / \mathrm{min}$ and scanned over a range of $20^{\circ} \mathrm{C}$ to $400{ }^{\circ} \mathrm{C}$ at a heating rate of $5^{\circ} \mathrm{C} / \mathrm{min}[24]$.

\section{$\mathrm{X}$-ray diffraction}

The X-ray diffraction pattern of the nanospheres optimized formulation, physical mixture, free drug and polymers were analyzed using an X-ray powder diffractometer (XRD Bruker AXS, D8 focus, Karlsruhe, Germany) using $\mathrm{Cu}$ Ka radiation. The data of the samples were measured in reflection mode of $4^{\circ} \leq 2 \theta \leq 80^{\circ}$ on flat aluminum sample holders scanned at $40 \mathrm{KV}$ and $30 \mathrm{~mA}$. The diffractogram of each sample was recorded at a step size of 0.02 and dwell time of $0.6 \mathrm{sec}$ [2].

\section{Fourier transform infrared (FT-IR) spectroscopy}

The FTIR spectroscopic analysis is executed to investigate the potential interaction between the drug and the polymers utilized for the preparation of the nanospheres using PerkinElmer spectrum FTIR (ES version, Massachusetts, United states). Samples of $2 \mathrm{mg}$ were thoroughly triturated with potassium bromide and subsequently compacted at 10 tones. The spectra were scanned over a frequency range 400 to $4000 \mathrm{~cm}^{-1}$ with $4 \mathrm{~cm}^{-1}$ resolution [24].

\section{RESULTS AND DISCUSSION}

\section{Preparation of tadalafil-loaded polymeric nanospheres}

Electrohydrodynamic atomization is a promising technique for the fabrication of drug-loaded polymeric nanoparticles. In the current study, a series of tadalafil-loaded nanospheres formulations compromising various concentrations of PVP and PEO were successfully prepared via electrohydrodynamic atomization. The drug was entrapped in the nanoparticles by co-solving the drug and the polymers in methanol before the atomization process. Different formulation parameters were studied in order to investigate their influence on the particle morphology and drug release kinetics. The presence of a secondary polymer as well as the overall polymer concentration were chosen as variables of interest. PVP was selected as the matrix-forming polymer as it presents favorable properties such as low toxicity, hydrophilicity, and ability to enhance drug dissolution [24]. Furthermore, the secondary polymer introduced was PEO which was used due to its semi-crystallinity properties which in turn can reduce the hygroscopic property of PVP [25].

To determine the optimal concentrations and influence of the polymers mixture on the dissolution of tadalafil and nanosphere morphology, different formulations present in table 1 were prepared.

Table 1: Nanospheres formulations: composition and characteristics

\begin{tabular}{|c|c|c|c|c|c|c|}
\hline Formulation & $\begin{array}{l}\text { PVP concentration } \\
\%(w / w)\end{array}$ & $\begin{array}{l}\text { PEO concentration } \\
\%(w / w)\end{array}$ & $\begin{array}{l}\text { Yield } \\
\%\end{array}$ & $\begin{array}{l}\text { Loading } \\
\text { efficiency } \%\end{array}$ & $\begin{array}{l}\% \text { in vitro release at } 2 \\
\text { min }\end{array}$ & $\begin{array}{l}\text { Particle } \\
\text { size (nm) }\end{array}$ \\
\hline F1 & 2.5 & 0 & $88 \pm 4.50$ & $80 \pm 2.10$ & $83 \% \pm 5.41$ & $1190 \pm 31$ \\
\hline $\mathrm{F} 2$ & 2.5 & 2.5 & $87 \pm 3.13$ & $86 \pm 3.62$ & $80 \% \pm 3.25$ & $785 \pm 28$ \\
\hline F3 & 2.5 & 5 & $90 \pm 2.46$ & $88 \pm 2.71$ & $76 \% \pm 4.94$ & $1279 \pm 141$ \\
\hline F4 & 5 & 0 & $86 \pm 4.84$ & $91 \pm 3.50$ & $89 \% \pm 4.42$ & $642 \pm 41$ \\
\hline F5 & 5 & 2.5 & $90 \pm 5.38$ & $93 \pm 3.20$ & $86 \% \pm 5.14$ & $374 \pm 13$ \\
\hline F6 & 5 & 5 & $89 \pm 2.00$ & $95 \pm 2.45$ & $84 \% \pm 2.55$ & $865 \pm 31$ \\
\hline
\end{tabular}




\section{Electrospray powder process yield}

Electrohydrodynamic atomization is a single-step process for the formation of drug-loaded nanoparticles, which has been employed pharmaceutically in different drug delivery applications [10]. The one-step pathway of the electrohydrodynamic atomization technique depends on the formulation and process parameters to articulate the optimal preparation features.

The study evaluated the concentrations of the PVP and PEO polymers on the nanospheres yield collected after the atomization process. The process yield didn't exceed $90 \%$ ranging between $86-90 \%$ as presented by table 1 . The collection of the nanospheres was maintained on a collection sheet, although the yield was mostly high in most samples and no reasonable correlation between the concentration of the polymer and the overall yield, yet the loss occurring to the yield can be related to the scattering of the nanoparticles to the outer surrounding and attachment on the nozzle. This was reported in Bohr et al. preparation of celecoxib loaded nanoparticles where the loss of the yield was related to dispersing in the surrounding [2].

\section{Drug loading efficiency}

A major asset of the successfulness of a certain technique evolves around the ability and the range of drug loading within the formulation, as it affects the dose and therapeutic efficacy of the final formulation.

The loading efficacy of the tadalafil in the various formulations ranged between $80-95 \%$ as represented in table 1 . The significant differences between the different formulations highlighted that the increase in PVP concentration was advantageous for drug loading ( $p$ value $<0.05$ ). This phenomena might the by its ability to maintain higher uptake at increased concentration. Similarly, the PEO concentration positively improved the drug loading which can be linked to PEO ability to increase tadalafil solubility within the formulation [26]

\section{In vitro drug release within 2 min}

The influence of the polymer concentration on the dissolution of tadalafil was statistically investigated through ANOVA, which indicated significant fluctuations $(\mathrm{p}<0.05)$. The nanospheres were prepared with varying concentrations of the polymers at a fixed drug content. The different formulations, physical mixture and free drug were studied over $60 \mathrm{~min}$ at $37 \pm 0.5^{\circ} \mathrm{C}$ in $900 \mathrm{ml} 0.1 \mathrm{~N}$ HCL. The various formulations release patterns fluctuated with the polymer concentrations. This was evident in the first two minutes, where all formulations maintained a relatively completed release. Within the first $2 \mathrm{~min}$ of drug release, it was clear that PVP concentration affected the amount of drug released, where the increase in PVP concentration increased the dissolution rate, the hydrophilic characteristic of the polymer can explain this. Similar results were recognized in a study carried out by Yousaf et al. where the authors prepared fenofibrate nanoparticle formulations and investigated the effect of PVP concentration where the increase of PVP ratio to drug 4:1 enhanced the drug dissolution beyond which the increase of PVP ratio didn't have any significant effect on the fenofibrate dissolution [24]. On the other hand, PEO concentration reduced tadalafil release rate, where a delay of drug release was noticeable, this effect can be due to the interaction between the PVP and PEO which increased the diffusion layer thickness thus prolonging the time required for the drug to diffuse and released [27](Hong, Oh, 2008).

The dissolution enhancement is clear where more than $80 \%$ of the loaded drug was released within 2 min while the drug/polymer's physical mixture demonstrated a minor release of $8.5 \%$ and an insignificant release for the free drug of $5.3 \%$ within the same period. The release of the physical mixture and the free drug didn't change noticeably over 60 min where the physical mixture release didn't exceed $15 \%$ while the drug maintained at $5.5 \%$ as illustrated by fig. 1 .

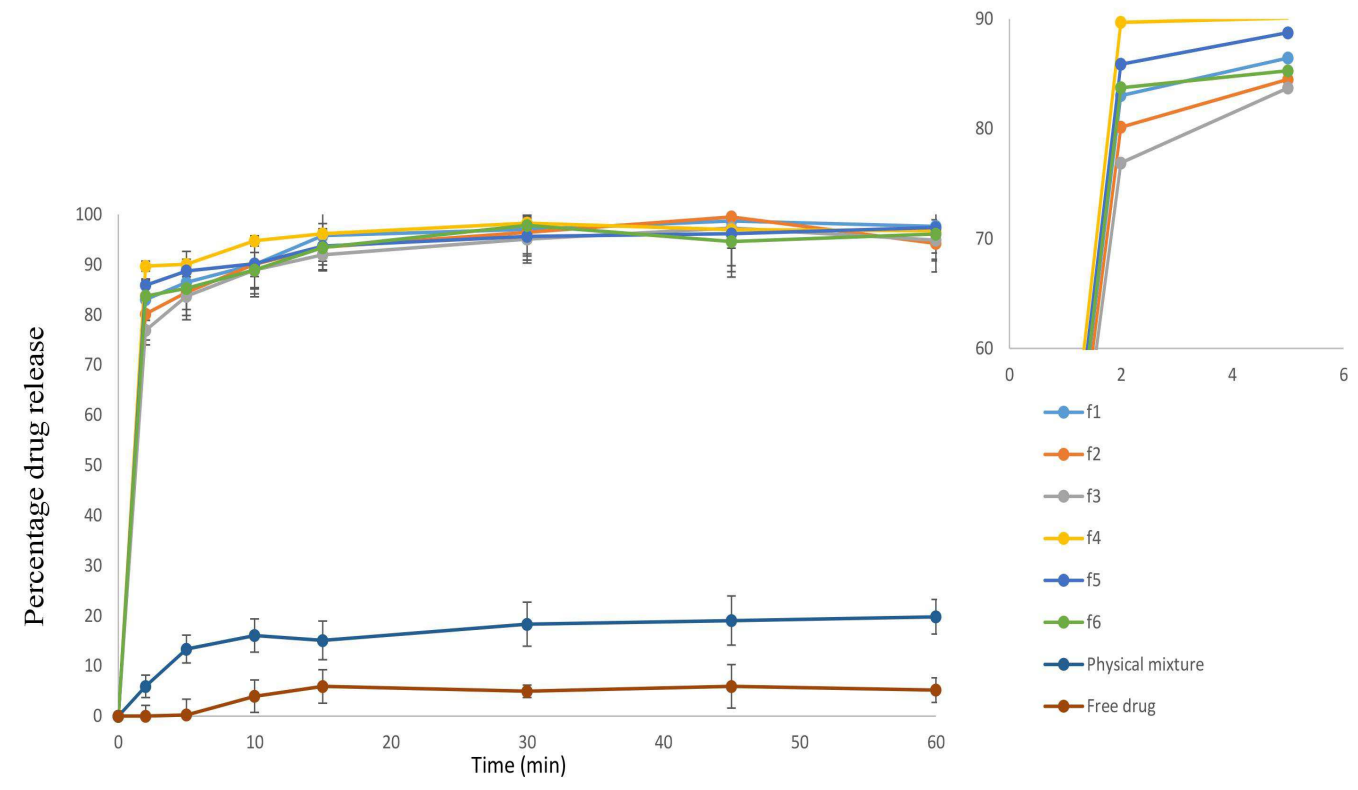

Fig. 1: In vitro release of tadalafil-loaded nanospheres formulations in $0.1 \mathrm{HCL}$ at $37 \pm 0.5^{\circ} \mathrm{C}$

\section{Electron microscopical evaluation}

Photomicroscopical images of the various formulations were examined to assess the influence of the polymer concentrations on the nanosphere morphology. The polymers used highly affected the nanosphere morphology as enlightened in fig. 2 , where the increase in PVP from $2.5 \%$ to $5 \%$ enhanced the uniformity of the particle size ( $p$ value $<0.05$ ). Inclusion of PEO at $2.5 \%$ resulted in a reduction of aggregation, although 5\% negatively affect the nanosphere size and morphology where particles became non-uniform and few fibers were observed. This can be attributed to the increased viscosity of the solution which led to fiber formation [28]. The electromicroscopical imaging indicates a nanoparticle size range between $374 \pm 13 \mathrm{~nm}$ to $1279 \pm 141 \mathrm{~nm}$ depending on the polymer concentrations, with the optimal size range and uniform morphology presented by F5 containing PVP and PEO concentration at $5 \%$ and $2.5 \%$, respectively. 

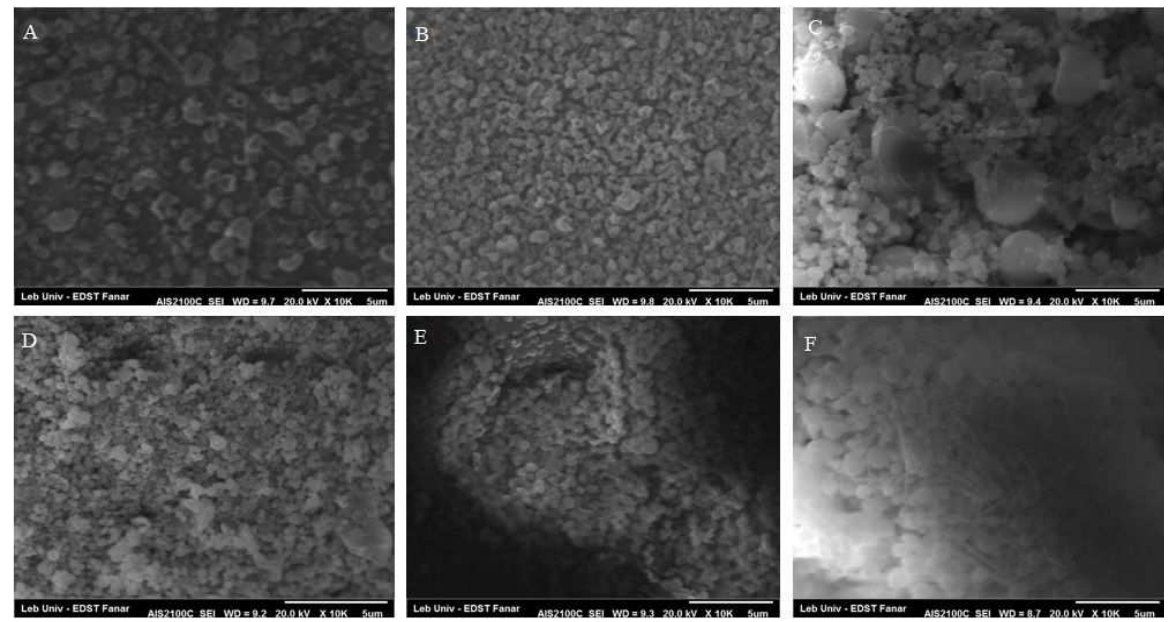

Fig. 2: Scanning electron microscopical images of tadalafil-loaded nanospheres samples, F1 (A), F2 (B), F3 (C), F4(D), F5(E), F6 (F)

\section{Solid-state characterization}

\section{Differential scanning calorimetry (DSC)}

The thermal properties of the drug-loaded nanoparticles, free drug, polymers, and the physical mixture were studied using DSC. The free drug presented a sharp endothermic peak at $305.49{ }^{\circ} \mathrm{C}$ with an enthalpy of fusion of $98.78 \mathrm{~J} / \mathrm{g}$ (fig. 3A), this confirms the crystalline nature of the drug [18]. The polymer PVP didn't generate any endothermic peaks yet demonstrated a fusion peak at $62.64{ }^{\circ} \mathrm{C}$ (fig.
3B), this is attributed to the moisture evaporation [24]. The PEO semi-crystalline nature is observed by the characteristic peak at $68.18^{\circ} \mathrm{C}$ (fig. 3C) [29]. The physical mixture thermograph preserved the characteristic peak of PEO yet the thermal drug behavior was absent which can be explained by the melting of the drug within the polymers upon heating (fig. 3). Formulation 5 thermograms presented a complete absence of the characteristic peaks of tadalafil which indicate that the drug is present in a molecular state or transformed into the amorphous form [24].
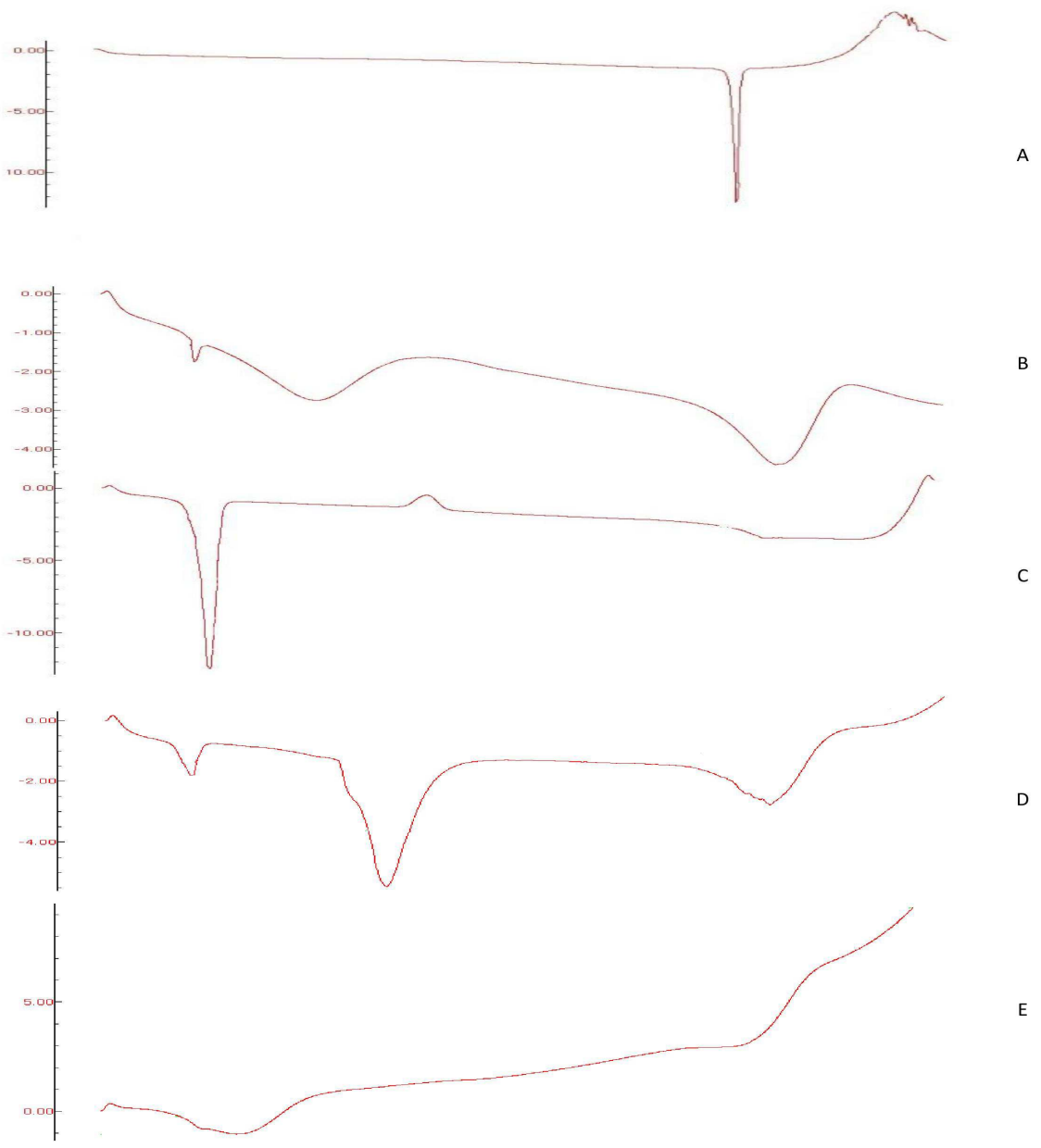

Fig. 3: DSC thermograms of (A) tadalafil (B) PVP, (C) PEO, (D) physical mixture,(E) tadalafil-loaded nanospheres 


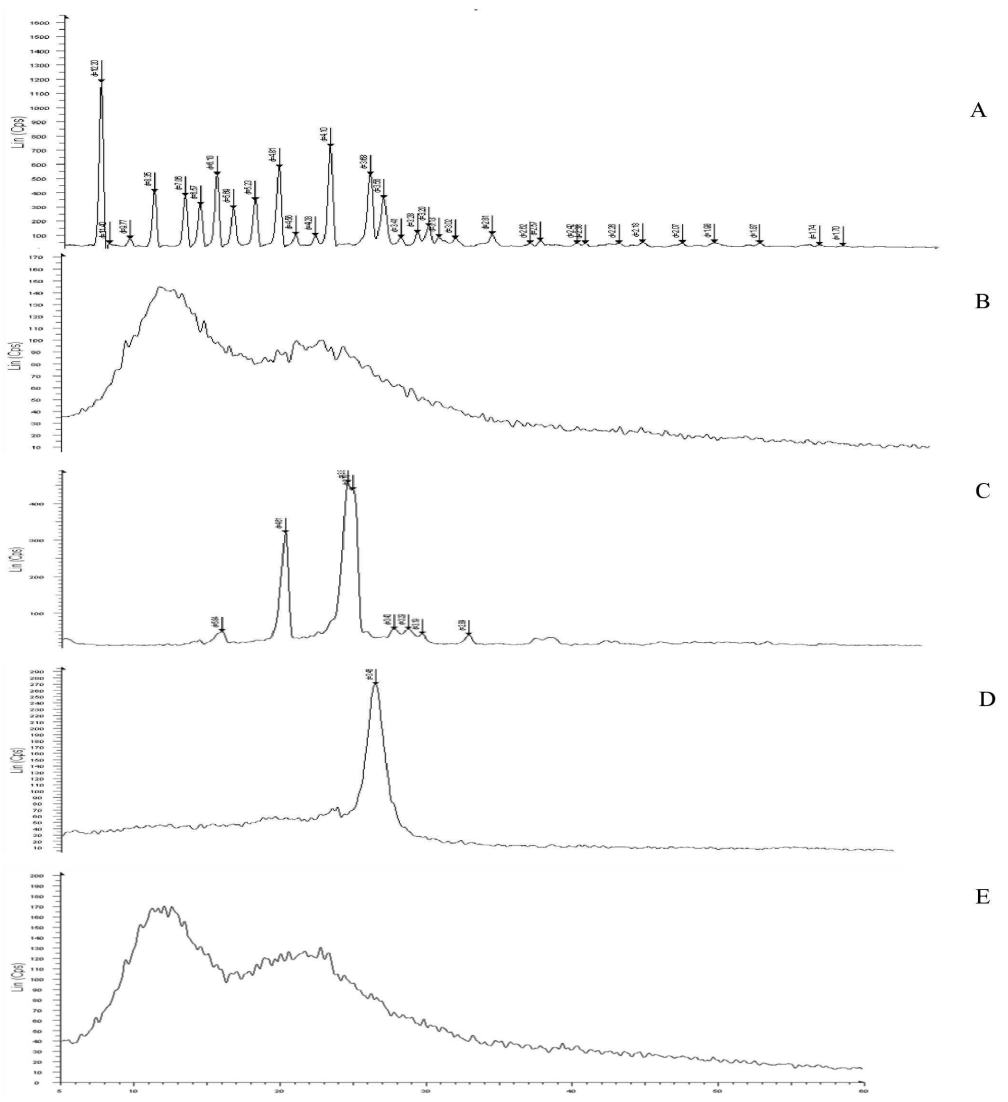

Fig. 4: X-ray diffraction patterns of (A) tadalafil (B) PVP, (C) PEO, (D) physical mixture, (E) tadalafil-loaded nanospheres
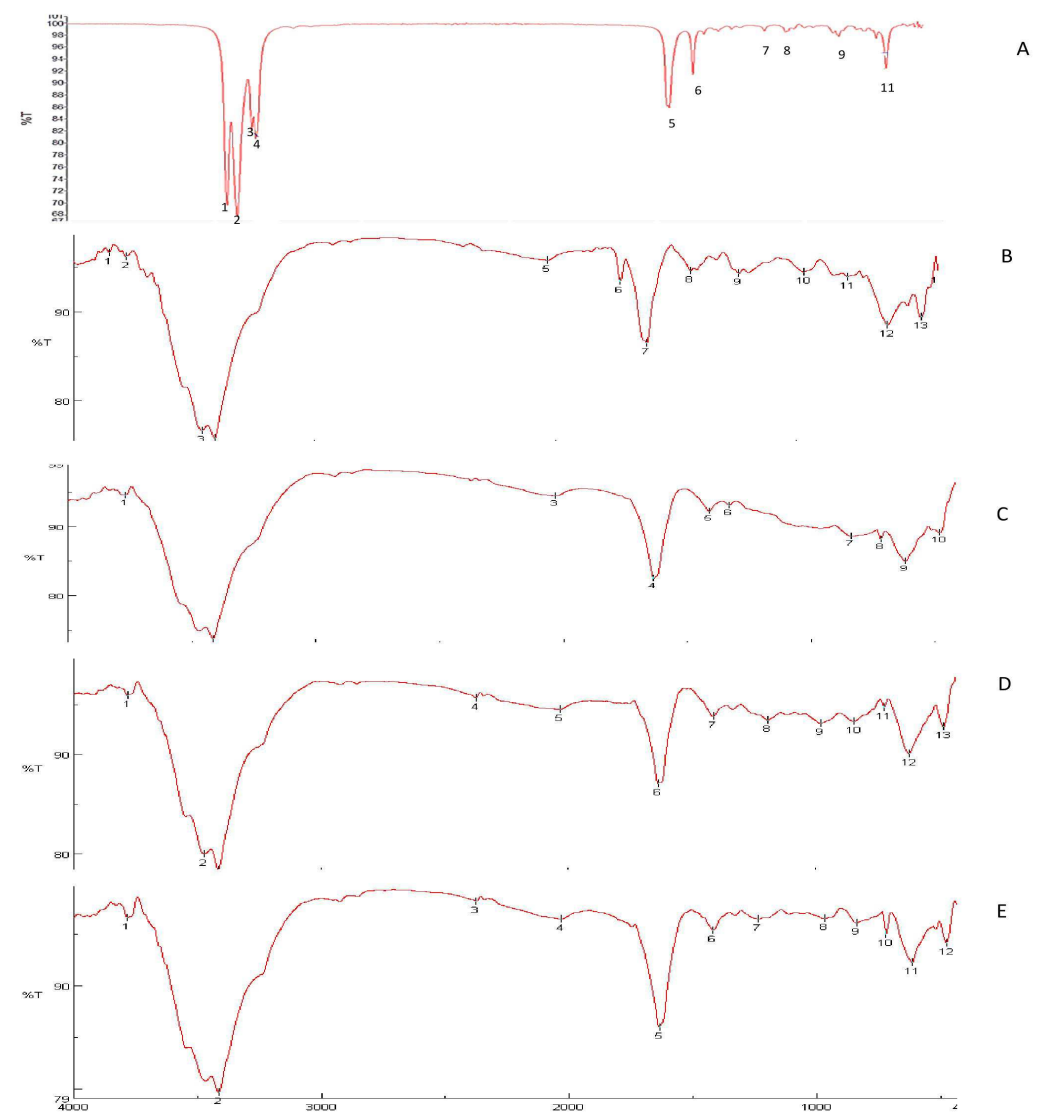

Fig. 5: FTIR spectra of (A) tadalafil (B) PVP, (C) PEO, (D) physical mixture, (E) tadalafil-loaded nanospheres 


\section{X-Ray diffraction}

The X-ray diffraction patterns of the drug-loaded nanoparticle, free drug, polymers and their physical mixture are displayed in fig. 4. The free drug pattern is characterized by sharp peaks which indicate its crystalline structure as indicated by Mehanna et al. [21]. The diffraction of PVP didn't show any sharp peak indicating it amorphous nature, on the other hand, sharp peaks are present for PEO which emphasizes its semi-crystalline nature [30]. The physical mixture reveals a broadening and decreased intensity of the characteristic peaks of the drug and PEO polymer. The partial modification of the intensities of the crystalline nature peaks was reported by Yu et al., which was attributed to the masking effect of PVP matrix [31]. The formula (F5) diffraction pattern revealed the absence of crystallinity peaks of tadalafil which ensures the drugs amorphous state or molecular dispersion within the nanosphere matrix.

\section{FTIR spectroscopy}

The FTIR spectra of the different samples are illustrated in fig. 5 were utilized to investigate the compatibility between the drug and polymers in the formulation. The characteristic absorption bands of the drug indicate a carbonyl stretch, and $\mathrm{C}-\mathrm{H}$ aromatic stretching at $1675.3 \mathrm{~cm}^{-1}$ and $3057.5 \mathrm{~cm}^{-1}$, respectively [21]. The PVP spectra reveals a C-H stretching and vibration carbonyl group at $2954 \mathrm{~cm}^{-1}$ and $1662 \mathrm{~cm}^{-1}$ respectively [31]. A triplet peak C-O-O stretch is observed for PEO indicating its semi-crystalline nature at around $1145 \mathrm{~cm}^{-1}$ to $1059 \mathrm{~cm}^{-1}$ [32]. The characteristic peaks of the drug and the polymer appeared in the physical mixture as well as the nanosphere formula (F5). The peak pattern mirror image between the nanosphere and the physical mixture indicates the absence of interaction between tadalafil and the polymers (PVP/PEO) in the formulation [24].

\section{CONCLUSION}

Electrohydrodynamic atomization was able to fabricate tadalafilloaded nanospheres composed of PVP, PEO at varying polymer concentrations in a simple single step straight forward technique. The nanospheres diameter ranged from $374 \pm 13 \mathrm{~nm}$ up to $1279 \pm 141$. The formulations elucidated a high loading ability in the nanospheres with a rapid dissolution rate of $89 \%$ release within 2 min. The physicochemical examination indicated the presence of the drug in an amorphous state or molecularly dispersed within the nanoparticles matrix. Electrohydrodynamic atomization technique is a potential drug development system for the dissolution enhancement and oral bioavailability augmentation of low aqueous solubility drugs.

\section{ACKNOWLEDGMENT}

The authors are grateful for the Lebanese National Council for Scientific Research (CNRS) Grant Award for Lebanese graduates.

\section{FUNDING}

Nil

\section{AUTHORS CONTRIBUTIONS}

All the authors have contributed equally.

\section{CONFLICT OF INTERESTS}

\section{Declared none}

\section{REFERENCES}

1. Gomez Estaca J, Balaguer MP, Gavara R, Hernandez Munoz P. Formation of zein nanoparticles by electrohydrodynamic atomization: effect of the main processing variables and suitability for encapsulating the food coloring and active ingredient curcumin. Food Hydrocoll 2012;28:82-91.

2. Bohr A, Kristensen J, Dyas M, Edirisinghe M, Stride E. Release profile and characteristics of electrosprayed particles for oral delivery of a practically insoluble drug. J R Soc Interface 2012;9:2437-49.

3. Xie J, Marijnissen JCM, Wang CH. Microparticles developed by electrohydrodynamic atomization for the local delivery of an anticancer drug to treat C6 glioma in vitro. Biomaterials 2006;27:3321-32.

4. Zolkepali NK, Abu bakar NF, Naim MN, Anuar N, Kamalul Aripin $\mathrm{NF}$, Abu Bakar MR, et al. Formation of fine and encapsulated mefenamic acid form I particles for dissolution improvement via electrospray method. Part Sci Technol 2018;36:298-307.

5. Vemula VR, Lagishetty V, Lingala S. Solubility enhancement techniques. Int J Pharm Sci Rev Res 2010;5:41-51.

6. Yu H, Teo J, Chew JW, Hadinoto K. Dry powder inhaler formulation of high-payload antibiotic nanoparticle complex intended for bronchiectasis therapy: spray drying versus spray freeze drying preparation. Int J Pharm 2016;499:38-46.

7. Das S, Banerjee R, Bellare J. Aspirin loaded albumin nanoparticles by coacervation: implications in drug delivery. Trends Biomater Artif Organs 2005;18:203-12.

8. Kwon HY, Lee JY, Choi SW, Jang Y, Kim JH. Preparation of PLGA nanoparticles containing estrogen by an emulsificationdiffusion method. Colloids Surf A 2001;182:123-30.

9. Desgouilles S, Vauthier C, Bazile D, Vacus J, Grossiord JL, Veillard $\mathrm{M}$, et al. The design of nanoparticles obtained by solvent evaporation: a comprehensive study. Langmuir 2003;19:9504-10.

10. Zamani M, Prabhakaran MP, Ramakrishna S. Advances in drug delivery via electrospun and electrosprayed nanomaterials. Int J Nanomed 2013;8:2997-3017.

11. Abdel-Aziz A-AH, Asiri YA, El-Azab A, Al-Omar MA, Kunieda T. Tadalafil. Profiles Drug Subst Excipients Relat Methodol 2011;36:287-329.

12. Doggrell SA. Comparison of clinical trials with sildenafil, vardenafil and tadalafil in erectile dysfunction. Expert Opin Pharmacother 2005;6:75-84.

13. Lu M, Xing H, Yang T, Yu J, Yang Z, Sun Y, et al. Dissolution enhancement of tadalafil by liquisolid technique. Pharm Dev Technol 2017;22:77-89.

14. Refaat A, Sokar M, Ismail F, Boraei N. Tadalafil oral disintegrating tablets: an approach to enhance tadalafil dissolution. J Pharm Investig 2015;45:481-91.

15. Badr-Eldin SM, Elkheshen SA, Ghorab MM. Inclusion complexes of tadalafil with natural and chemically modified??cyclodextrins. I: preparation and in vitro evaluation. Eur J Pharm Biopharm 2008;70:819-27.

16. Obeidat WM, Sallam ASA. Evaluation of tadalafil nanosuspensions and their PEG solid dispersion matrices for enhancing its dissolution properties. AAPS PharmSciTech 2014;15:364-74.

17. Vinesha V, Sevukarajan M, Rajalakshmi R, Chowdary GT, Haritha K. Enhancement of solubility of tadalafil by cocrystal approach. Int Res J Pharm 2016;4:218-23.

18. Mehanna MM, Motawaa AM, Samaha MW. Tadalafil inclusion in microporous silica as an effective dissolution enhancer: optimization of loading procedure and molecular state characterization. J Pharm Sci 2011;100:1805-18.

19. Shen X, Yu D, Zhu L, Branford White C, White K, Chatterton NP. Electrospun diclofenac sodium loaded Eudragit?? L 100-55 nanofibers for colon-targeted drug delivery. Int J Pharm 2011;408:200-7.

20. Mehanna MM, Alwattar JK, Elmaradny HA. Optimization, physicochemical characterization and in vivo assessment of spray-dried emulsion: a step toward bioavailability augmentation and gastric toxicity minimization. Int J Pharm 2015;496:766-79.

21. Mehanna MM, Motawaa AM, Samaha MW. Insight into tadalafilblock copolymer binary solid dispersion: mechanistic investigation of dissolution enhancement. Int J Pharm 2010;402:78-88.

22. Sakuma S, Matsumoto S, Ishizuka N, Mohri K, Fukushima M, Ohba C, et al. Enhanced boosting of oral absorption of lopinavir through electrospray coencapsulation with ritonavir. J Pharm Sci 2015;104:2977-85.

23. Li C, Yu DG, Williams GR, Wang ZH. Fast-dissolving core-shell composite microparticles of quercetin fabricated using a coaxial electrospray process. PLoS One 2014;9:1-9.

24. Yousaf AM, Mustapha O, Kim DW, Kim DS, Kim KS, Jin SG, et al. Novel electrosprayed nanospherules for enhanced aqueous 
solubility and oral bioavailability of poorly water-soluble fenofibrate. Int J Nanomed 2016;11:213-21.

25. Zhou Y, Qi P, Zhao Z, Liu Q, Li Z. Fabrication and characterization of fibrous HAP/PVP/PEO composites prepared by sol-electrospinning. RSC Adv 2014;4:16731.

26. Bhattarai N, Edmondson D, Veiseh O, Matsen FA, Zhang M. Electrospun chitosan-based nanofibers and their cellular compatibility. Biomaterials 2005;26:6176-84.

27. Hong SI, Oh SY. Dissolution kinetics and physical characterization of the three-layered tablet with poly(ethylene oxide) core matrix capped by carbopol. Int J Pharm 2008;356:121-9.

28. Nasir $M$, Matsumoto $H$, Danno $T$, Minagawa $M$, Irisawa $T$, Shioya M, et al. Control of diameter, morphology, and structure of PVDF nanofiber fabricated by electrospray deposition. J Polymer Sci Part B: Polymer Physics 2006;44:779-86.

29. Huang L, Nagapudi K, Apkarian RP, Chaikof EL. Engineered collagen-PEO nano bers and fabrics. J Biomater Sci Polym Edn 2001;12:979-93.

30. Ajao JA, Abiona AA, Chigome S, Fasasi AY, Osinkolu GA, Maaza $M$. Electric-magnetic field-induced aligned electrospun poly (ethylene oxide) (PEO) nanofibers. J Mater Sci 2010;45:2324-9.

31. Yu DG, Branford White C, Shen XX, Zhang XF, Zhu LM. Solid dispersions of ketoprofen in drug-loaded electrospun nanofibers. J Dispers Sci Technol 2010;31:902-8.

32. Noor SAM, Ahmad A, Talib IA, Rahman MYA. Morphology, chemical interaction, and conductivity of a PEO-ENR50 based on solid polymer electrolyte. Ionics (Kiel) 2010;16:161-70. 